\title{
A Novel and Low-Cost Modified Sternal Closure Technique in Open Heart Surgery (Yerebakan Technique)
}

\author{
Kenan Abdurrahman Kara ${ }^{1}$, Fatma Ferda Kartufan², Soner Sanioğlu ${ }^{1}$, Hakan Öntaş ${ }^{3}$ and Halit Yerebakan*1 \\ ${ }^{1}$ Department of Cardiovascular Surgery, Yeditepe University Hospital, Istanbul, Turkey \\ ${ }^{2}$ Department of Anesthesia and Intensive Care, Yeditepe University Hospital, Istanbul, Turkey \\ ${ }^{3}$ Department of Cardiovascular Surgery, Balikesir City Hospital, Turkey
}

Received: 眥: September 20, 2018; Published: 制 September 25, 2018

*Corresponding author: Halit Yerebakan, Department of Cardiovascular Surgery, Yeditepe Univesity Hospital, Istanbul, Turkey

\begin{abstract}
Objectives: Sternal dehiscence that may occur after an open heart surgery is a serious complication that may result in morbidity and mortality from pain in sternum and separation of wound lips to pulmonary dysfunction, superficial and deep mediastinal infection [1-4]. Sternal movement and instability may occur on the first day or weeks later after the surgery depending on the risk factors of the patient, sternal closure material or surgical technique. Sternal closure materials are being used more frequently and increase the costs [5]. We are presenting a study where we closed the sternum of 20 patients in our clinic with a novel technique using a standard steel wire.

Methods: We closed the sternum of 40 patients who underwent open heart surgery in the cardiovascular surgery clinic at Yeditepe University Faculty of Medicine Hospital between January 2017-May 2018 with a new technique.

Results: Patients were assessed at 1 week and 1 month in the early post-operative period and following discharge. Sternal instability, dehiscence or sternum superficial wound site infection or mediastinitis were not detected in the early period. None of the patients used a sternum corset in the post-operative period.

Conclusion: Today, median sternotomy is still the most frequently used method in heart surgery routine despite the advancements in minimal invasive techniques. Sternal dehiscence may be seen at the rate of $0.2 \%-5 \%$ following open heart surgery [6-9]. We think that an excellent sternal fixation and stability is ensured with the technique we used without increasing the costs.
\end{abstract}

Keywords: Sternal dehiscence; Sternum closure technique; Mediastinitis

\section{Introduction}

Median sternotomy is the most common incision for cardiac surgery. It provides safety and easy exposure for surgeon. Following the cardiac surgery by median sternotomy, sternum is closed by surgical steel wires. However post-operative mechanical sternal dehiscence of sternum is still a frightening and devastating complication for both patients and surgeons. This may result ranging from increased postoperative pain to sternal wound infection and mediastinitis and readmissions in post-operative period.

Readmission rates for coronary artery bypass graft (CABG) surgery range from 15 to $21 \%$. Readmissions result in increased hospital costs, but even more importantly, have been associated with increased morbidity and mortality. So, reducing readmissions following cardiac surgery should be major priority for whatever it takes [5]. There is a growing diversity of sternal wiring techniques, from single wire to more modified "figure of eight"-wires and cable closure techniques, even dynamic fixation plates have been discussed and used properly (Figure 1). Most of the cardiac surgery patients are severe obese, diabetic, with obstructive pulmonary disease, are mostly smokers and old. After Cardiac surgery due to mechanical sternal dehiscence cause mediastinitis is a multifactorial disease with an incidence between 0.5 and $5 \%$. The main independent risk factors are: obesity, diabetes, smoking, Chronic Obstructive Pulmonary Disease, use of pedicled internal thoracic artery and prolonged on-pump time [8-11].

Sternal complications were seen to be higher in patients undergoing bilateral pedicled IMA. Rather than conventional closure methods, closure methods such as sternal plating, sternal band have gained importance particularly in these patients. However, the most important problem at this point is the high cost of sternal closure products. With the modified technique we used in our study, sternum was closed with a steel wire used in routine practice without using a sternal closure product. Sternal dehiscence is mostly seen in lower $1 / 3$ part of the sternum [2-4]. In our modified technique we use double steel wires for perfect stabilization for the inferior part of sternum. With this technique, 
excellent stabilization was ensured and dehiscence was avoided. Sternum corset was not used in any of the patient's post-operation. Sternal closing technique used in our study is reported to prevent cutting of sternal cortex as tension on sternum is applied on more balanced area, unlike to conventional sternal steel wires $[10,11]$. It provides better stabilization and perfect closing of inferior $1 / 3$ part of sternum. The aim of this study is to present 20 patients on whom we used a sternal closure method which is quite practical and lowcost and just as effective.

\section{Patients and Method}

We closed the sternum of 40 patients who underwent open heart surgery at the cardiovascular surgery clinic at Yeditepe University Faculty of Medicine Hospital between January 2017-May 2018 with a new technique (28 males, 12 females; mean age: 53,8 ). Sternum upper zone was closed with the routine Figure- 8 method after the open heart surgery. In the middle and lower zone of the sternum, 2 of the 4 steel wires, which were close to each other, were first fixed the same side of the sternum, and then the sternum was fixed with the wires on the opposite site. Therefore, a strong inseparableness was created in the middle and lower zone of the sternum. Patients with renal failure or who had a cerebrovascular event were excluded from the study.

Surgery was performed through a median sternotomy. Following sternotomy, the IMAs were exposed using a sternal retractor and the left IMA was harvested first. When a single LIMA was used, it was harvested in pedicled fashion. When BIMA were used, they were both harvested in skeletonized fashion. After that cardiopulmonary bypass established selective venous cannulation through vena cava superior and vena cava inferior and ascending aortic cannulation in mitral valve patients. CABG patients after median sternotomy right atrial and asendan aorta cannulation was performed. Blood cardioplegia was used in the initial and Intermittent cold cardioplegia thereafter. Hypothermic cardiopulmonary bypass was started with rectal temperature lowered to $30^{\circ} \mathrm{C}$ or $32^{\circ} \mathrm{C}$. An intravenous second-generation cephalosporin antibiotic was administered intraoperatively and for 48 hours postoperatively for prophylaxis against infection.

Table 1: Preoperative demographic characteristics.

\begin{tabular}{|c|c|}
\hline Patient number & 40 \\
\hline Age (Years) & 53,8 \\
\hline COPD & $16(\% 40)$ \\
\hline DM & $24(\% 60)$ \\
\hline Obesity & $($ BMI $>3010(\% 25)$ \\
\hline Osteoporosis & $12(\% 30)$ \\
\hline Bilateral Mammary artery & $16(\% 40)$ \\
\hline ICU Day & 2,6 \\
\hline Hospital Day & 7,2 \\
\hline
\end{tabular}

COPD: Chronic Obstructive Pulmonary Disease; DM: Diabetes Mellitus; BMI: Body Mass Index; NS: Non-Significant.

Patients were followed up for a mean of 2,6 days in intensive care. They were then taken into the general ward and discharged after a mean of 7.2 days. The patients were assessed in terms of operative mortality, intensive care and hospitalization length, incision site pain, Mediastinitis, post-operative healing complications and reoperation (Table 1).

\section{Statistics Analysis}

No statistical tests were used. Data was expressed as mean \pm standard deviation.

\section{Results}

Patients were assessed at 1 week and 1 month in the early post-operative period and following discharge. Sternal instability, dehiscence or sternum superficial wound site infection or mediastinitis were not detected in the early period. None of the patients used a sternum corset in the post-operative period.

\section{Discussion}

Due to an aging population and increasing number of comorbidities, the operative risk has risen over the years. In the last decades, studies reported an improvement in cardiac surgery techniques, perioperative and postoperative management. As a result, despite the trend towards a worsening surgical risk profile, the combined morbidity and mortality rate remained unchanged. The prevalence of multimorbid patients undergoing cardiac surgery is progressively increasing. As a result of this cardiac surgeons are performing a growing number of sternotomies in high-risk patients. This phenomenon is the consequence of an aging population and an increase in comorbidity [9-19].

Closing of sternum is the most important factor for sternal dehiscence. During sternal closing done by conventional approach using steel wires $5 / 0$ or $6 / 0$, bone cortex erosion, fracture and consequently sternal dehiscence can occur due to compression of steel wires. Sternal dehiscence may lead to respiratory dysfunction, infection, increased pain and re-exploration [20]. The frightening complication of post-operative mechanical sternal dehiscence is the infection starting with the separation of wound lips and subsequently spreading to the lower layers and sternum and resulting in mediastinitis. Considering that the starting point is sternal dehiscence, it comes to mind how important the right sternal closure is.

Mediastinitis is a devastating complication, which can lead to prolonged hospitalization, high hospital costs, high associated morbidity and even mortality. It is important to focus not only on efficient aseptic preoperative preparations and surgical techniques but even more on postoperative prevention techniques. With increasing evidence that patients who received bilateral internal mammary artery (BIMA) grafts have better long-term outcomes than those receiving single internal mammary artery (SIMA) grafts. BIMA grafting is increasingly adopted as the routine. Since the technique employed for harvesting the internal mammary artery (IMA) varies, the incidence of sternal wound complications (SWCs) varies from $1.5 \%$ to $6.9 \%$. With the conventional wide-pedicled dissection of the BIMAs, sternal infection rates of $1.7 \%$ to $6.9 \%$ have been reported. A full skeletonizing technique has been used 
in some institutions with reported sternal infection rates of $1.5 \%$ to $1.9 \%$ [21-25].

\section{Conclusion}

We think that the modified technique we used in this study with routine sternum steel wires provides a more durable and stable sternal closure compared to the conventional sternal closure in the middle and lower zone of the sternum. Also, a robust fixation was created in the sternum without using sternal closure products such as sternal plating, sternum screw etc. which are high cost. Given the sternum improvement problems especially in patients who are diabetic, obese or using BITA, this result is promising. The small number of patients is the most important limitation of this study. Also, the follow-up of patients until 1 month after the operation is another limitation in terms of medium- and long-term outcomes.

\section{Scientific Responsibility Statement}

The authors declare that they are responsible for the article's scientific content including study design, data collection, analysis and interpretation, writing, some of the main line, or all of the preparation and scientific review of the contents and approval of the final version of the article.

\section{Animal and Human Rights Statement}

All procedures performed in this study were in accordance with the ethical standards of the institutional and/or national research committee and with the 1964 Helsinki declaration and its later amendments or comparable ethical standards. No animal or human studies were carried out by the authors for this article.

\section{References}

1. Sá MP, Soares EF, Santos CA, Figueiredo OJ, Lima RO, et al. (2011) Risk factors for mediastinitis after coronary artery bypass grafting surgery. Rev Bras Cir Cardiovasc 26(1): 27-35.

2. Kalush SL, Bonchek LI (1976) Peristernal closure of median sternotomy using stainless steel bands. Ann Thorac Surg 21(2): 172-173.

3. Johnston RH, Garcia-Rinaldi R, Vaughan GD, Bricker D (1985) Mersilene ribbon closure of the median sternotomy: An improvement over wire closure. Ann Thorac Surg 39(1): 88-89.

4. Ozaki W, Buchman SR, Iannettoni MD, Frankenburg EP (1998) Biomechanical study of sternal closure using rigid fixation techniques in human cadavers. Ann Thorac Surg 65(6): 1660-1665.

5. Harold L Lazar (2018) Reducing readmission risk following CABG surgery-Doing whatever it takes. Journal of cardiac surgery 33(4): 171.

6. Dalton ML, Connally SR (1993) H Milton: Visionary surgeon. Am J Surg 165(3): 355-357.

7. Schwann TA, Habib RH, Zacharias A, Parenteau GL, Riordan CJ, et al (2001) Effects of body size on operative, intermediate and long-term outcomes after coronary artery bypass operation. Ann Thorac Surg 71(2): 521-530.

8. Zacharias A, Habib RH (1996) Factors predisposing to median sternotomy complications. Deep vs superficial infection. Chest 110(5): 1173-1178.
9. Loop FD, Lytle BW, Cosgrove DM, Mahfood S, McHenry MC, et al. (1990) J Maxwell Chamberlain memorial paper. sternal wound complications after isolated coronary artery bypass grafting: Early and late mortality, morbidity, and cost of care. Ann Thorac Surg 49(2): 179-186.

10. Szabó Z, Håkanson E, Svedjeholm R (2002) Early postoperative outcome and medium-term survival in 540 diabetic and 2239 nondiabetic patients undergoing coronary artery bypass grafting. Ann Thorac Surg 74(3): 712-719.

11. Risnes I, Abdelnoor M, Almdahl SM, Svennevig JL (2010) Mediastinitis after coronary artery bypass grafting risk factors and long-term survival. Ann Thorac Surg 89(5): 1502-1509.

12. Zerr KJ, Furnary AP, Grunkemeier GL, Bookin S, Kanhere V, et al. (1997) Glucose control lowers the risk of wound infection in diabetics after open heart operations. Ann Thorac Surg 63(2): 356-361.

13. Furnary AP, Gao G, Grunkemeier GL, Wu Y, Zerr KJ, et al. (2003) Continuous insulin infusion reduces mortality in patients with diabetes undergoing coronary artery bypass grafting. J Thorac Cardiovasc Surg 125(5): 1007-1021.

14. Friedrich-Christian Riess, Nizar Awwad, Bettina Hoffmann (2004) A Steel Band in Addition to 8 Wire Cerclages Reduces the Risk of Sternal Dehiscence after Median Sternotomy. The Heart Surgery Forum 7(6): 387-392.

15. Robiscek F, Fokin A, Cook J, Bhatia D (2000) Sternal Instability After Midline Sternotomy. Thorac Cardiov Surg 48(1): 1-8.

16. Buxton BF, Komeda M, Fuller JA, Gordon I (1998) Bilateral internal thoracic artery grafting may improve outcome of coronary artery surgery. Risk-adjusted survival. Circulation 98(Suppl 2): 1-6.

17. Calafi ore AM, Vitolla G, Iaco AL, Fino C, Di Giammarco G, et al. (1999) Bilateral internal mammary artery grafting: midterm results of pedicled versus skeletonized conduits. Ann Thorac Surg 67(6): 1637-1642.

18. Galbut DL, Traad EA, Dorman MJ, DeWitt PL, Larsen PB, et al. (1990) Seventeen-year experience with bilateral internal mammary artery grafts. Ann Thorac Surg 49: 195-120.

19. Sofer D, Gurevitch J, Shapira I, Paz Y, Matsa M, et al. (1999) Sternal wound infections in patients after coronary artery bypass grafting using bilateral skeletonized internal mammary arteries. Ann Surg 229(4): 585-590.

20. Kara KA, Erk Z, Koçyiğit A, Gulmen Ş, Öcal A, et al. (2018) The Comparison Between Two Sternum Closure Techniques after Coronary Bypass Surgery; Sterna-band (Peninsula) and Sternum Band (Ethicon). Adv Card Res 1(2).

21. Lytle BW, Blackstone EH, Loop FD, Houghtaling PL, Arnold JH, et al. (1999) Two internal thoracic artery grafts are better than one. J Thorac Cardiovasc Surg 117(5): 855-872.

22. Kouchoukos NT, Wareing TH, Murphy SF, Pelate C, Marshall WG Jr. (1990) Risks of bilateral internal mammary artery bypass grafting. Ann Thorac Surg 49(2): 210-217.

23. Loop FD, Lytle BW, Cosgrove DM, Mahfood S, McHenry MC, et al. (1990) J Maxwell Chamberlain memorial paper. Sternal wound complications after isolated coronary artery bypass grafting: Early and late mortality, morbidity, and cost of care. Ann Thorac Surg 49(2): 179-186.

24. Grossi EA, Esposito R, Harris LJ, Crooke GA, Galloway AC, et al. (1991) Sternal wound infections and use of internal mammary artery grafts. J Thorac Cardiovasc Surg 102(3): 342-346.

25. Matsa M, Paz Y, Gurevitch J, Shapira I, Kramer A, et al. (2001) Bilateral skeletonized internal thoracic artery grafts in patients with diabetes mellitus. J Thorac Cardiovasc Surg 121(4): 668-674. 


\section{ISSN: 2574-1241}

DOI: 10.26717/BJSTR.2018.09.001785

Halit Yerebakan. Biomed J Sci \& Tech Res

(C) (P) This work is licensed under Creative

Submission Link: https://biomedres.us/submit-manuscript.php

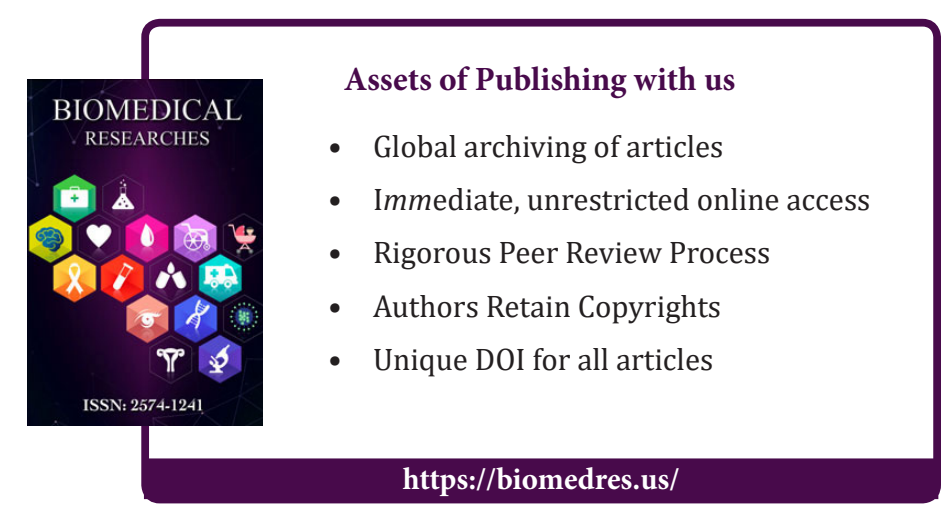

